\title{
Ruh Sağlığı Çalışanlarının Madde Kullanım Bozukluğu Tedavisine Yönelik Tutumları Ölçeğinin Geliştirilmesi
}

\author{
Aylin IŞIK ${ }^{1}$, Gülsüm Melike ŞİMŞEK ${ }^{1}$
}

\begin{abstract}
Özet: Bu çalışmanın amacı bağımlılık tedavisinde hizmet vermeyen ruh sağlı̆̆ı uzmanlarının bağımlılık tedavisi hakkındaki inanışlarını ölçen geçerli ve güvenilir bir ölçek geliştirmektir. Ölçeğin geçerlik güvenirlik çalışmaları 65 psikiyatrist ve 86 psikologun (298 kız, 281 erkek) katılımıyla gerçekleştirilmiştir. Psikologlar ölçeği internet tabanlı bir anket formundan, psikiyatristler ise bir ulusal kongrede manuel olarak doldurmuştur. Geliştirme çalışmasında açımlayıcı faktör analizine başvurulmuş, madde ayırt edicilikleri belirlenmiş, Cronbach Alpha güvenirlik sayısı hesaplanmıştır. Bu analizler sonucunda 3 faktörlü (duygusal yaklaşım, mantıksal yaklaşım ve çalışmaya karşı tutum) toplam varyansın \%33'ünü açıklayan 12 maddeden oluşan ölçek elde edilmiştir. Ölçeğin tümü için Cronbach Alpha katsayısı .77 olarak hesaplanmıştır. Elde edilen sonuçlar ölçeğin geçerli ve güvenilir olduğunu kanıtlar niteliktedir.
\end{abstract}

Anahtar Kelimeler: Bağımlılık, Ölçek, Ruh Sağlı̆̆ı Uzmanı, Stigma

\section{Development Of Mental Health Professionals' Attitudes Toward Treatment Of Substance Use Disorders}

\begin{abstract}
The aim of the current study is to develop a valid and reliable scale that measures the beliefs of mental health professionals who do not work in addiction about alcohol and substance addiction treatment. The validity and reliability studies of the scale were conducted with the participation of 65 psychiatrists and 86 psychologists (298 female, 281 male). The data of the study were collected using questionnaire from an interned-based questionnaire and manually filled it at a national congress. In the development study, exploratory factor analysis was applied, item discrimination was determined and Cronbach Alpha reliability coefficients was calculated. As a result of this analys, a 3 factored (emotional approach, logical approach and attitude towards work) scale that explains $33 \%$ of the total variance and that was comprised of 11 items was obtained. Cronbach's $\alpha .77$ coefficients for the totality of the scale were calculated.The obtained results prove that the scale is valid and reliable.
\end{abstract}

Key words: Addiction, Scale, Mental Health Professionals, Stigma

${ }^{1}$ Uzm. Psk., Yeşilay Danışmanlık Merkezi (YEDAM), aylin.isik@ yesilay.org.tr

Address of correspondence/ Yazışma adresi: Uzm. Psk., Aylin Işık, Yeşilay Danışmanlık Merkezi (YEDAM), E-mail: aylin.isik@yesilay.org.tr

Date of Received/Geliş Tarihi: 25.10.2019, Date of Revision/Düzeltme Tarihi: 02.11.2019, Date of Acceptance/Kabul Tarihi: 06.11.2019

Citing/ Referans Gösterimi: Işık, A., Şimşek G.M. (2019). Development Of Mental Health Professionals' Attitudes Toward Treatment Of Substance Use Disorders. Kıbrls Türk Psikiyatri ve Psikoloji Dergisi, 1(Ö̈zel Sayl.1): 24-26 doi:10.35365/ctjpp.19.special1.6 


\section{Giriş}

Damgalanma veya olumsuz tepkilerden korkma, insanların genel olarak zihinsel sağlı sorunları için profesyonel yardım aramamasının temel nedenidir (Barney ve ark. 2006, Schomerus ve Angermeyer, 2008 ). Damgalama, bağımlılık tedavisi alan hastaların tedavisini stresli ve zorlayıcı hale getirir (Deans and Soar, 2005 , Ford, 2011, Van Boekel ve ark., 2013b ). Bu nedenle bağımlı bireylerin tedavi aramasını engelleyebilmektedir (Brener ve ark, 2010). Ayrıca tedavi sürse dahi sağlık çalışanlarının olumsuz tutumları, tedavi sirasinda okulu birakma ve ya nüks etme ihtimalini artırabilir (Ball ve ark., 2006 ). Bir çok insan barınma, istihdam ve sigorta politikaları dahil olmak üzere madde bağımlılarına fayda sağlayan politikaları desteklememektedir (Barry ve ark, 2014).Bir çalışmada bağımlıların en fazla aile, arkadaş ve sağlık çalışanları tarafından damgalandığını rapor edilmiştir (Livingston ve ark, 2012; Barry ve ark, 2014; Baldwin ve ark, 2010). Bazı sağlık çalışanlarının, bağımlı kişilerle çalışma konusunda rahatsızlık duydukları ve böylece ihtiyaç duyulan yardımları sağlama becerilerini kullanamadıkları bulunmuştur. Bağımlı bireylerin sakinleştirici ve ağrı kesici ilaçları almak için yalan söylediklerini ve güvenilmez olduklarını düşünmektedir. Bağımlılığı irade eksiliği ve kişisel zayıflık ile açıklanması farklı popülasyonlardaki olumsuz tutumları arttırmaktadır (Schomerus ve ark., 2011). Örneğin, uyuşturucu kullanımını "kontrol edilebilir" olarak gören sağlık çalışanlarının, damar yolu ile uyuşturucu kullanıcılarına karşı daha fazla önyargılı tutumlarının olduğu bulunmuştur (Brener ve Hipel, 2008; Brener, Hippel, Kippax ve Preacher, 2010). Damgalayıcı tutumlar bağımlı bireylerin tedavi aramasını engelleyebilmektedir (Brener ve ark, 2010). $\mathrm{Bu}$ çalışmanın temel amacı, Türkiye'de bağımlılık alanında çalışmayan psikolog ve psikiyatristlerin bağımlılık tedavisine yönelik tutumlarını anlamak ve endişelerini incelemektir. $\mathrm{Bu}$ nedenle, Türkiye'de bağımlılık tedavisine yönelik tutum araştırmalarında kullanılabilecek güçlü ölçüm özeliklerine sahip bir ölçek geliştirmektedir.

\section{Yöntem}

\section{Ölçeğin geliştirilmesi}

Ölçek literatür taraması ve uzman görüşleri değerlendirilerek oluşturulmuştur (Crothers ve Dorrian, 2011; Gilchrist ve ark., 2011). Yanıt seçenekleri, 0-5 puan arasında değerlendirilen altılı Likert tipi ölçekten oluşmuştur. Ölçekten alınabilecek puan 0-55 arasındadır. Yanıt skalaları "(5) Tamamen katıliyorum”, “(4) katılıyorum", "(3) Kararsızım ama sanırım katılıyorum", "(2)kararsızım ama sanırım katılmıyorum", “(1) Katılmıyorum” , “(0) Hiç katılmıyorum” şeklinde düzenlenmiştir.

\section{Örneklem ve Uygulama}

Toplamda 111'i $(\% 73,5)$ kadın ve 40'1 $(\% 26,5)$ erkek; 65 'i $(43,0)$ bağımlılık alanında çalışmayan psikiyatrist ve 86'sı $(\% 57,0)$ bağımlılık alanında çalışmayan psikolog olmak üzere 151 ruh sağlığı çalışanına ulaşıldı. Veriler, 2019 yılı Mart ve Nisan aylarında toplandı. Psikiyatristlere bir ulusal psikofarmakoloji kongresinde rastgele dağıtıldı. Psikologlar ise mail yoluyla ölçek doldurma daveti alarak ölçeği doldurdu.

\section{Sonuç}

Ölçekten alınan puanın ortalaması 36.26 \pm 7.14 bulunmuştur. Ölçeğin iç tutarlık analizinde Cronbach Alfa katsayısı 0.77 saptanmıştır (Tablo 1).

\begin{tabular}{|c|c|c|c|c|}
\hline & $\begin{array}{l}\text { Madde } \\
\text { çıktığında ölçek } \\
\text { ortalaması }\end{array}$ & $\begin{array}{l}\text { Madde } \\
\text { çıtığında } \\
\text { ölçek varyansı }\end{array}$ & $\begin{array}{l}\text { Madde-toplam } \\
\text { korelasyonu }\end{array}$ & $\begin{array}{l}\text { Madde } \\
\text { çıktığında ölçek } \\
\text { Cronbach alfa } \\
\text { katsayısı }\end{array}$ \\
\hline 1. Böyle hastalarla çalışmak tatmin edicidir. & 33,45 & 41,77 & 0,49 & 0,75 \\
\hline 2. Sağlık sigortası böyle hastaları da kapsamalıdır. & 32,14 & 47,04 & 0,21 & 0,77 \\
\hline $\begin{array}{l}\text { 3. Böyle hastalara yardım etmek için yapabileceğimiz çok az } \\
\text { şey var. }\end{array}$ & 32,65 & 42,82 & 0,39 & 0,76 \\
\hline $\begin{array}{l}\text { 4. Böyle hastalara karşı özellikle şefkatli /merhametli } \\
\text { hissediyorum. }\end{array}$ & 33,27 & 43,94 & 0,35 & 0,76 \\
\hline 5. Böyle hastalar beni rahatsız ediyor. & 32,54 & 39,91 & 0,70 & 0,72 \\
\hline $\begin{array}{l}\text { 6. Böyle hastalar için acil durumlar için gece yarısı } \\
\text { çağrrlmak beni rahatsı etmez. }\end{array}$ & 33,68 & 42,35 & 0,32 & 0,77 \\
\hline 7. Böyle hastalar için harcanan para bir kayıptır. & 31,90 & 46,87 & 0,37 & 0,76 \\
\hline $\begin{array}{l}\text { 8. Böyle hastalar benim için özellikle çalışması zor } \\
\text { hastalardır. }\end{array}$ & 33,58 & 42,39 & 0,40 & 0,76 \\
\hline $\begin{array}{l}\text { 9. Genellikle böyle hastaların daha iyi hissetmelerine } \\
\text { yardımcı olacak bir şeyler bulabilirim. }\end{array}$ & 32,87 & 41,90 & 0,65 & 0,73 \\
\hline $\begin{array}{l}\text { 10. Böyle hastalara fazladan zaman ayırmaktan keyif } \\
\text { alıyorum. }\end{array}$ & 33,64 & 40,24 & 0,60 & 0,73 \\
\hline 11. Böyle hastalarla çalışmak tehlikelidir. & 32,86 & 44,63 & 0,29 & 0,77 \\
\hline
\end{tabular}

Verilerin faktör analize uygun olup olmadığını araştırmak için KMO and Barlett's testi uygulanmıştır. KMO değeri 0.78 bulunarak verilerin faktör analizine uygun olduğu tespit edilmiştir (KMO > .050; p < 0.05). Faktör analizi sonucunda ölçeğin maddelerinin, toplam varyansın \%33'ünü açıklayan 3 faktör altında toplandığ saptanmıştır (Tablo 2). Bunlar; duygusal yaklaşım, mantıksal yaklaşım ve çalışmaya karşı tutum olarak açıklanmıştır. Bu bulgular Bağımlılık Tedavisi Stigma Ölçeği'nin bağımlılık tedavisini damgalamayı ölçmede yeterli bir araç olduğunu desteklemektedir. 
Tablo 2: YEDAM Madde Bağımlılığı Stigma Ölçeğinin Faktör Yapısı

\begin{tabular}{|c|c|c|c|}
\hline & Faktör 1 & Faktör 2 & Faktör 3 \\
\hline 1. Böyle hastalarla çalışmak tatmin edicidir. &, 535 & & \\
\hline 2. Sağlık sigortası böyle hastaları da kapsamalıdır. & & &, 822 \\
\hline 3. Böyle hastalara yardım etmek için yapabileceğimiz çok az șey var. & ,465 & & \\
\hline 4. Böyle hastalara karşı özellikle şefkatli /merhametli hissediyorum. & ,795 & & \\
\hline 5. Böyle hastalar beni rahatsız ediyor. & ,716 & & \\
\hline 6. Böyle hastalar için acil durumlar için gece yarısı çağrılmak beni rahatsız etmez. & & &, 396 \\
\hline 7. Böyle hastalar için harcanan para bir kayıptır. & & &, 785 \\
\hline 8. Böyle hastalar benim için özellikle çalışması zor hastalardır. & & ,662 & \\
\hline $\begin{array}{l}\text { 9. Genellikle böyle hastaların daha iyi hissetmelerine yardımcı olacak bir şeyler } \\
\text { bulabilirim. }\end{array}$ & 645 & & \\
\hline 10. Böyle hastalara fazladan zaman ayırmaktan keyif alıyorum. & ,802 & & \\
\hline 11. Böyle hastalarla çalışmak tehlikelidir. & & ,834 & \\
\hline
\end{tabular}

\section{Tartışma}

Damgalamanın, bağımlıların tedavi için profesyonel yardım aramasının önündeki bir engel olduğu düşünülecek olursa ruh sağlığı uzmanlarının damgalayıcı tutumlarının tespit edilmesi önemlidir. Ruh sağllğı uzmanlarının ölçekten aldığı toplam puan ortalamanın üstündedir. Örneklemini psikolog ve psikiyatristlerin oluşturduğu bu araştırmada ulaşılan toplam damgalama skorunun ortalamanın üzerinde olması, bağımlılık ile ilgili mevcut eğitim ve sağlık çalışmalarının yeniden düzenlemesi gerektiğini göstermektedir. Bu alandaki çalışmalar özellikle uzmanların damgalayıcı tutumlarına değinmeli, geleceğin hekimleri ve psikologlarının bağımlı bireylere daha faydalı hizmet verme, bireyi bilgilendirme ve yönlendirmesi için bağımlılık tedavisi hakkında doğru bilgiye sahip olmalıdır. $\mathrm{Bu}$ bağlamda uzmanların bilgilenmesi ve bağımlıya davranışlarını olumsuz etkileyecek ön yargıll tutumlarına yönelik programlar gerçekleştirilmelidir. Geliştirilen ölçeğin Türkiye'de yapılacak tutum araştırmalarında ve müdahale programlarında kullanılması ümit edilmektedir.

\section{Kaynaklar}

Baldwin, M. L., Marcus, S. C., De Simone, J. (2010). Job loss discrimination and former substance use disorders. Drug and alcohol dependence, 110(1-2), 1-7.

Ball, S.A., Carroll, K.M., Canning-Ball, M., Rounsaville, B.J., (2006). Reasons for dropout from drug abuse treatment: symptoms, personality, and motivation. Addict. Behav. 31, 320-330.

Barry, C. L., McGinty, E. E., Pescosolido, B. A., Goldman, H. H. (2014). Stigma, discrimination, treatment effectiveness, and policy: public views about drug addiction and mental illness. Psychiatric services (Washington, D.C.), 65(10), 1269-72.

Barney L.J., Griffiths K.M., Jorm, A.F., Christensen, H. (2006). Stigma about depression and it impact on helpseeking intentions. Australian and New Zealand Journal of Psychiatry 40, 51-54.

Brener, L., Hippel V.W., Kippax, S., Preacher, K.J. (2010). The Role of Physician and Nurse Attitudes in the Health Care of Injecting Drug Users, Substance Use and Misuse, 45(7-8), 1007-1018.

Brener, L., Hippel V.W. (2008). Measuring attitudes toward injecting drug users and people with hepatitis C. Substance Use and Misuse, 43(3-4), 295-302.
Deans, C., Soar, R., 2005. Caring for clients with dual diagnosis in rural communities in Australia: the experience of mental health professionals. J. Psychiatr. Ment. Health Nurs. 12, 268-274.

Ford, R., 2011. Interpersonal challenges as a constraint on care: the experience of nurses' care of patients who use illicit drugs. Contemp. Nurse, 37, 241-252.

Schomerus G., Angermeyer M.C., Matschinger H. \& Riedel-Heller S.G. (2008). Public attitudes towards prevention of depression. Journal of Affective Disorders, $106,257-263$.

Schomerus, G., Lucht, M., Holzinger, A., Matschinger, H., Carta, M.G., Angermeyer, M.C. (2011) The Stigma of Alcohol Dependence Compared with Other Mental Disorders: A Review of Population Studies, Alcohol and Alcoholism, 46(2) 105-112.

Van Boekel, L.C., Brouwers, E.P.M., Van Weeghel, J., Garretsen, H.F.L., 2013b. Stigma among health professionals towards patients with substance use disorders and its consequences for healthcare delivery: systematic review. Drug Alcohol Depend. 131, 23-35. 